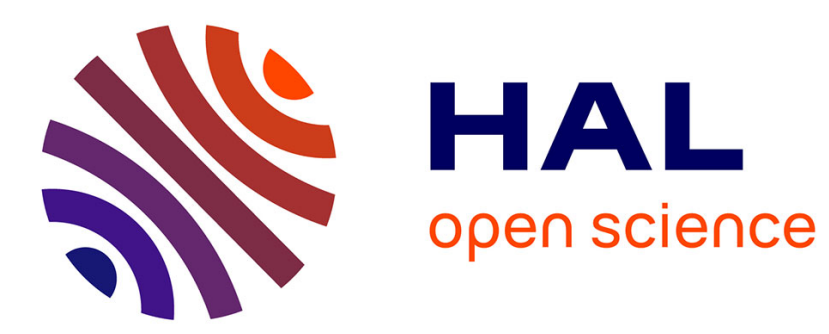

\title{
Grid-connected Kite Generator System: Electrical Variables Control with MPPT
}

Mariam Ahmed, Ahmad Hably, Seddik Bacha

\section{To cite this version:}

Mariam Ahmed, Ahmad Hably, Seddik Bacha. Grid-connected Kite Generator System: Electrical Variables Control with MPPT. IECON 2011 - 37th Annual Conference of the IEEE Industrial Electronics Society, Nov 2011, Melbourne, Australia. hal-00619324

\section{HAL Id: hal-00619324 \\ https://hal.science/hal-00619324}

Submitted on 6 Sep 2011

HAL is a multi-disciplinary open access archive for the deposit and dissemination of scientific research documents, whether they are published or not. The documents may come from teaching and research institutions in France or abroad, or from public or private research centers.
L'archive ouverte pluridisciplinaire HAL, est destinée au dépôt et à la diffusion de documents scientifiques de niveau recherche, publiés ou non, émanant des établissements d'enseignement et de recherche français ou étrangers, des laboratoires publics ou privés. 


\section{Grid-connected Kite Generator System: Electrical Variables Control with MPPT}

\author{
Mariam Ahmed* \\ Grenoble Electrical Engineering \\ Laboratory (G2ELab) \\ 38402 Saint-Martin d'Heres, \\ France
}

\author{
Ahmad Hably** \\ GIPSA-lab -ENSE3 BP 46 \\ 38402 Saint-Martin d'Heres, \\ France
}

\author{
Seddik Bacha*** \\ Grenoble Electrical Engineering \\ Laboratory (G2ELab) \\ 38402 Saint-Martin d'Heres, \\ France
}

\begin{abstract}
This paper presents a control scheme of a closedorbit kite generator system (KGS), which is a wind-based energy producing system with a relaxation cycle. Such a system is divided into two main parts: a kite with its orientation mechanism and a power transformation system. Starting from a given closed orbit, the optimal tether's length rate variation (kite's tether radial velocity) and the optimal orbit's period are found. A trajectory-tracking control is developed for the kite's orientation. The power transformation system controls the kite's tether radial velocity and transforms the mechanical energy generated by the kite into electrical energy that can be added to the grid. A Matlab/simulink model of the KGS is employed to observe its behavior, and to insure the control of its mechanical and electrical variables. In order to improve the KGS's efficiency in case of changing wind speed, a maximum power point tracking (MPPT) algorithm is proposed.
\end{abstract}

\section{INTRODUCTION}

Modern civilization is very energy dependent, especially on its nonrenewable sources, that will run out sooner or later. Using renewable energy sources instead of those nonrenewable is very promising but it is accompanied with a lot of scientific challenges.

Because of this major interest in sustainable development, renewable energy systems, such as solar photovoltaic, wind and tidal ${ }^{1}$ systems, are heavily explored. An interesting type of these systems are those with relaxation cycles. Such a system must periodically consume and produce energy. Fig.1 shows an example of the power produced by a relaxationcycle system. Examples of such systems are: kite-based traction system and tidal systems that uses waves or swell energy. All mentioned systems are more or less intermittent, but do not pose major issues in terms of control. The problem is rather in improving their integration into the electric grid technically and economically. However, when considering power generation system with relaxation periodic phases another difficulty is added. It is to control the generation/recovery cycle of such a system in order to recover the maximum possible energy, while considering the constraints on the system itself, the primary source of energy, and the grid loads.

One of the investigated relaxation-cycle power generating

*Corresponding author

Mariam.AHMED@g2elab.grenoble-inp.fr

**Ahmad. Hably@grenoble-inp. fr

***Seddik. Bacha@g2elab.grenoble-inp. fr

${ }^{1}$ Tidal Systems should not be confused with the conventional hydraulic.

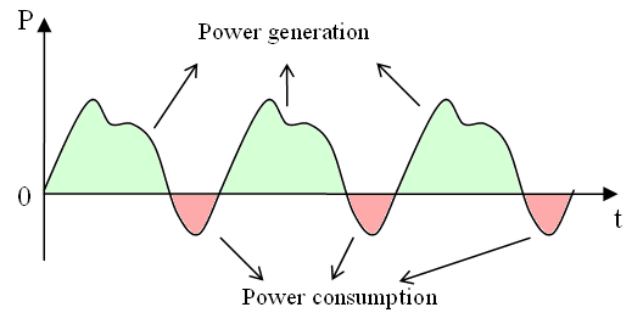

Fig. 1. Example of power profile of a limit-cycle system.

systems is the kite generator system (KGS). The KGS is a solution proposed to extract energy from the steady and strong wind found in high altitudes [6]. Its operation principle is to mechanically drive a ground-based electric generator using one or several tethered kites. A simple KGS structure is shown in Fig.2. In a closed-orbit scenario, energy is extracted from high altitudes by letting the kite fly at a closed lying-eight orbit with high crosswind speed [5]. While tracking the orbit, two phases can be distinguished: a traction phase, through which the KGS develops a large traction force that turns the electric machine, thus generates electricity, and a recovery phase, through which the kite is pulled by the machine, consuming energy as doing so. The objective is to improve the traction/recovery cycle through controlling the kite's position and movement around a predefined optimal trajectory that depends on wind's direction and speed.

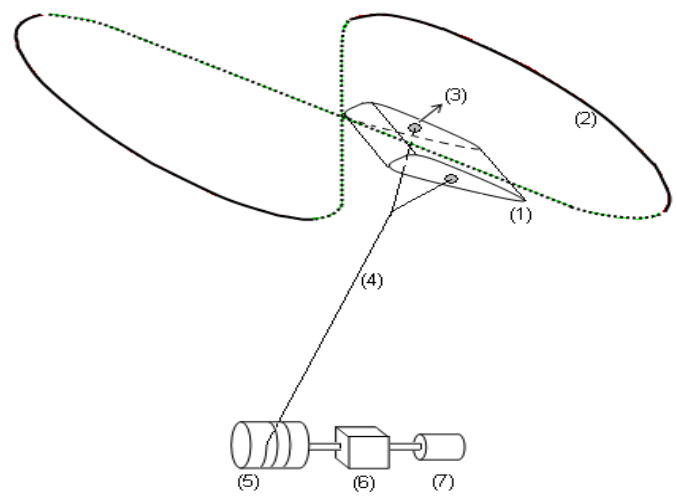

Fig. 2. Kite wind generator structure: 1) Kite; 2) Lying-eight orbit (dotted line: Traction phase, continuous line: Recovery phase) ; 3) Orientation mechanism; 4) Tether; 5) Drum; 6) Gearbox; 7) Electrical machine. 
The aim of this paper is to simulate the whole KGS using Matlab/Simulink. The mechanical and electrical variables can be observed and controlled, in order to provide a maximum electrical power that can be injected into the grid. To do so, an optimal approach proposed in [9] is applied to seek the optimal tether radial velocity and period corresponding to a certain orbit, as well as, to achieve orbit's tracking. The kite's traction torque and radial velocity are applied on a Simulink-model of a power transformation system.

The paper goes through four main sections. The first presents the kite generator system (KGS) studied structure. The modeling of each part of the KGS is presented in the second section. Section IV presents the control strategy, including the control of the electric machine which is a synchronous machine with permanent magnets MS-MP, and the control of the power electronics interface that connects the machine to the grid. In section $\mathrm{V}$, simulation results of a testing orbit are presented and discussed. The paper ends with conclusions and future work.

\section{Kite Generator System (KGS)}

As shown in Fig.3, a KGS is a kite that collects wind energy through drawing a lying-eight orbit, which ensures the non-tangling of the tether and the maximization of the apparent wind blowing against the kite, thus a high lift force applied on the kite's tether. The lift force is transformed into a torque applied on a synchronous machine with permanent magnets (SM-PM) situated on ground. This leads to producing an alternative electrical energy with variable frequency. The machine is coupled with the grid or with a certain load through a power electronics interface. An energy storage can be integrated in order to provide the necessary energy during the system's recovery phase. In the search of

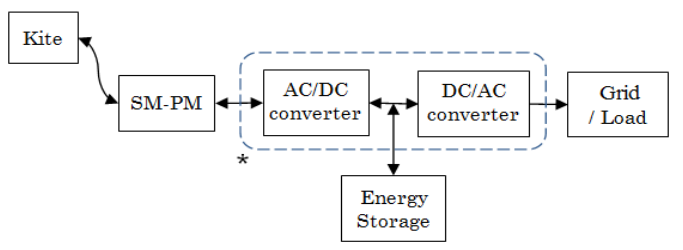

Fig. 3. Kite Generator System Block diagram, *Power electronics interface.

maximum/needed power generation the kite's model should be found, and a suitable orientation and velocity control should be applied, both of which need knowing wind speed. However, to give up the usage of on-board wind speed sensors, two methods are proposed: wind speed estimation [8], or usage of already existing curves of wind as a function of height, and then application of maximum power point tracking (MPPT) algorithm to ensure maximum/needed energy production.

\section{MODELING}

Finding the model of each part of the KGS is a very important step to achieve better understanding of its behavior, thus better controlling. This section presents the modeling of the kite and the power transformation system. Found models will be implemented on Matlab/Simulink in order to test the later-explained control strategy.

\section{A. The Kite's Model}

Two points are considered here: the forces acting on the kite that results in the traction force of the tether, and the kite's mechanical power generated by such a force.

1) Kite dynamics: The kite dynamic model originally developed in [4] and used in [3] is adapted here. Neglecting the tether weight and the tether's drag force, the forces acting on the kite written in the cylindric coordinates are

$$
\begin{aligned}
& F_{\theta}=F_{\theta}^{g r a v}+F_{\theta}^{a p p}+F_{\theta}^{a e r} \\
& F_{\phi}=F_{\phi}^{g r a v}+F_{\phi}^{a p p}+F_{\phi}^{a e r} \\
& F_{r}=F_{r}^{g r a v}+F_{r}^{a p p}+F_{r}^{a e r}-F^{c, t r c}
\end{aligned}
$$

where

- $F^{g r a v}$ is the gravity force

- $F^{a p p}$ is the apparent force given by

$$
\begin{aligned}
& F_{\theta}^{a p p}=m\left(\dot{\phi}^{2} r \sin \theta \cos \theta-2 \dot{r} \dot{\theta}\right) \\
& F_{\phi}^{a p p}=m(-2 \dot{r} \dot{\phi} \sin \theta-2 \dot{\phi} \dot{\theta} r \cos \theta) \\
& F_{r}^{a p p}=m\left(r \dot{\theta}^{2}+r \dot{\phi}^{2} \sin ^{2} \theta\right)
\end{aligned}
$$

with $m$ is the mass of the kite.

- $F^{a e r}$ is the aerodynamic force which has two components, the lift force $F_{L}$ that is perpendicular to the kite's surface, and the drag force $F_{D}$ which has the effective wind's direction. These forces are functions of the kite's surface, the air density and the drag and lift coefficients. The aerodynamic force direction is controlled by the roll angle $\psi$.

- $F^{c, t r c}$ is the traction force of the tether.

2) Mechanical Power Generation for the Kite's Simplified Mathematical Model: As mentioned earlier, for sake of simplicity the weight of the tether and its drag force are not taken into account in the system modeling. As well as it is considered that the kite has a high lift over drag ratio $C_{L} / C_{D}$, which is equivalent to a high value of the kite aerodynamic efficiency coefficient $G_{e}$.

The system average mechanical energy over one period $T$ is

$$
\bar{P}_{M}=\frac{1}{T} \int_{0}^{T} F^{c, t r c}(t) V_{L}(t) d t
$$

where $V_{L}$ is the tether length rate's variation (the radial tether's velocity).

According to [2], by changing the integral time variable $t \in[0, T]$ to the dimensionless parameter $\tau \in[0,2 \pi]$, and making use of the substitution $V_{L}(t)=V v(\tau)$, eq.(3) can be expressed as follows:

$$
\bar{P}_{M}(v)=\frac{1}{2} \rho_{a} A C_{L} G_{e}^{2} V^{3} J_{0}(v)
$$

where $V$ is the wind speed amplitude and

$$
J_{0}(v)=\frac{\int_{0}^{2 \pi}\left(w_{\|}-v\right) v h(\tau) d \tau}{\int_{0}^{2 \pi} \frac{h(\tau)}{w_{||}-v} d \tau}
$$

with $h(\tau)=\sqrt{d \theta^{2}+d \phi^{2} \sin ^{2}(\theta)}$ and $w_{\|}=\sin (\theta) \cos (\phi)$. As noticed, $J_{0}$ represents the normalized ${ }^{2}$ average po-

\footnotetext{
${ }^{2}$ Normalizing coefficient is : $\rho_{a} A C_{L} G_{e}^{2} V^{3}$
} 
wer $\bar{P}_{M}$. The aim is to find the $v$ 's profile that maximizes the power expressed in eq.5, and respects the kite's closed orbit condition

$$
\int_{0}^{2 \pi} \frac{v h(\tau)}{w_{\|}-v} d \tau=0
$$

This is done through application of the fixed-point algorithm proposed in [9].

\section{B. Power Transformation System}

To integrate the kite's generated mechanical power into the electrical grid, a power transformation system is needed to transform this energy into electrical power with grid's standard voltage and frequency. Such a system consists mainly of a synchronous machine with permanent magnets (SM-PM), a power electronics interface and a connection with the grid or the load. Each part of the power transformation system is modeled in the coming paragraphs.

1) Torque Transmission between the Kite and the SM-PM: It is expressed by the fundamental mechanical equation:

$$
C_{G}-C_{R}-D \Omega_{S}=J \frac{d \Omega_{G}}{d t}
$$

where

- $\Omega_{S}$ is the rotation velocity.

- $J$ is the total inertia of the kite and the machine's rotor.

- $C_{G}$ is the generator torque.

- $C_{R}$ is the kite's resistive torque.

- $D$ is the damping factor estimation.

which means that in order to control the rotation velocity, a control of the generator torque should be applied.

2) The SM-PM's Vector Model: Each machine's phase can be presented by the Behn-Eschenburg equivalent electric model of Fig.4. Each phase is presented by its resistance $R_{s}$, inductance $L_{s}$ and its electromagnetic force $e_{s *}$. The model supposes the existence of a regular air gap, linear characteristics of the magnetic circuit (no saturation), and a balanced sinusoidal three-phase current behavior. Moreover, the electromagnetic torque is expressed by

$$
C_{G}=p \cdot \operatorname{Imag}\left(\overline{i_{s}} \cdot \phi_{f s}^{*}\right)
$$

To visualize the three phases at the same time, variables'

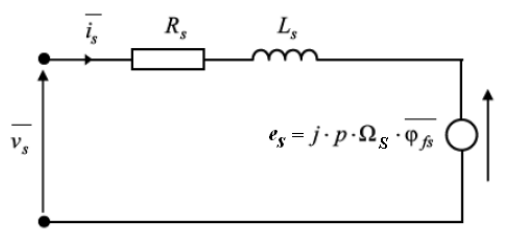

Fig. 4. SM-PM's Behn-Eschenburg equivalent electrical model.

vector presentation is used, which is expressed in Park coordinates $(p, q)$ by

$$
\begin{aligned}
v_{S d} & =R_{S} i_{S d}+L_{s} \frac{d i_{S d}}{d t}-\omega L_{S} i_{S q} \\
v_{S q} & =R_{S} i_{S q}+L_{s} \frac{d i_{S q}}{d t}+\omega L_{S} i_{S d}+\omega \phi_{f S d} \\
\phi_{S d} & =L_{S} i_{S d}+\phi_{f S d} \\
\phi_{S q} & =L_{S} i_{S q} \\
C_{G} & =p \phi_{f S d} i_{S q}
\end{aligned}
$$

where

- $\bar{v}_{s}=v_{S d}+j \cdot v_{S q}$ is stator voltages' vector.

- $\overline{i_{s}}=i_{S d}+j . i_{S q}$ is stator currents' vector.

- $p$ is the number of poles' pairs.

- $\bar{\phi}_{f s}=\phi_{f S d}+j . \phi_{f S q}$ is the induced flow vector.

- $\omega=p \Omega_{S}$.

3) Power Electronics Interface Modeling: An average model is adapted here, in order to have a continuous time model without switching, which allows the usage of relatively large sampling time in simulations.

The interface ensures frequency and voltage isolation between the SM-PM and the electrical grid or the connected loads, and at the same time it offers the possibility of power flow from/to the SM-PM. This interface is made up of two converters (AC/DC \& DC/AC) that insure the conversion of the variable frequency/voltage electric power generated by the MS-PM, into a standard frequency/voltage electric power that can be injected into the grid or supply a certain load. The structure chosen for this interface is two three-phase transistor-based voltage converters (Figs.5 and 6). Both are controlled using vector pulse width modulation (PWM). The SM-PM-side converter functions as a rectifier during the generation phase, and as an inverter during the recovery phase, insuring a bi-directional transfer of energy. Meanwhile the grid-side converter functions only as an inverter if a storage unit supplies the SM-PM-side inverter during the recovery phase. In the absence of a storage unit, it functions also as a rectifier to supply the SM-PM-side inverter directly from the electric grid. Supposing that the converter's transistors

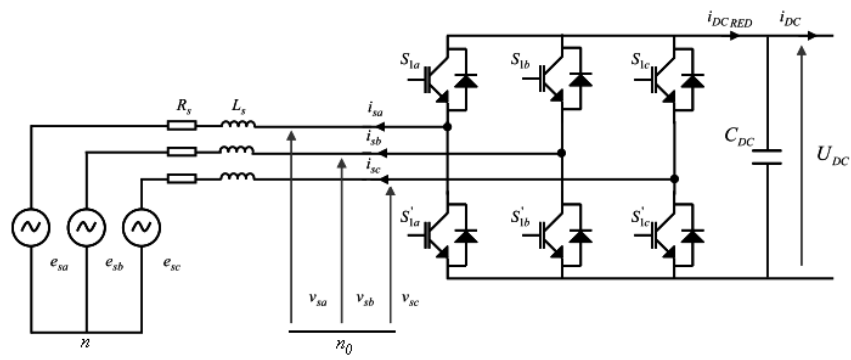

Fig. 5. Electric representation of the SM-PM-side converter. SM-PM is presented by Behn-Eschenburg model. $C_{d c}$ is DC-bus filtering capacitor.

and the voltage sources are perfect, as well as the passives elements are linear and constant, the average converter model is written as follows

$$
\begin{aligned}
& L_{s} \frac{d i_{s k}}{d t}=\beta_{s k} \frac{U_{D C}}{2}-e_{s k}-R_{s} i_{s k} \\
& C_{D C} \frac{d U_{D C}}{d t}=-I_{D C}+\sum\left(\beta_{s k} \frac{i_{s k}}{2}\right)
\end{aligned}
$$

where $k=a, b, c$ and $\beta_{s k}$ is the average value of the commutation function. By transforming eq.10 using Park representation, it can be illustrated that

$$
\begin{array}{ll}
L_{s} \frac{d i_{s d}}{d t} & =\beta_{s d} \frac{U_{D C}}{2}-\omega L_{q} i_{s q}-R_{s} i_{s d} \\
L_{s} \frac{d i_{s q}}{d t} & =\beta_{s q} \frac{U_{D C}}{2}-\omega L_{d} i_{s d}-R_{s} i_{s q}-e_{s q} \\
C_{D C} \frac{d U_{D C}}{d t} & =-I_{D C}+\left(\beta_{s d} \frac{i_{s d}}{2}+\beta_{s q} \frac{i_{s q}}{2}\right)
\end{array}
$$

where:

- $U_{D C}$ is the DC bus voltage. 
- $I_{D C}$ is the DC bus current.

The same modeling approach is applied in the case of the grid-side converter (Fig.6), which results in:

$$
\begin{aligned}
& L_{f} \frac{d i_{G d}}{d t}=\beta_{G d} \frac{U_{D C}}{2}-\omega_{G} L_{f} i_{G q}-R_{f} i_{G d}-\sqrt{3} V_{G} \\
& L_{f} \frac{d i_{G q}}{d t} \\
& C_{D C} \frac{d U_{D C}}{d t}=\beta_{G q} \frac{U_{D C}}{2}-\omega_{G} L_{f} i_{G d}-R_{f} i_{G q} \\
& I_{D C_{R E D}}-\left(\beta_{G d} \frac{i_{G d}}{2}+\beta_{G q} \frac{i_{G q}}{2}\right)
\end{aligned}
$$

where:

- $\omega_{G}$ is the electric grid pulsation of $v_{\text {res }}$.

- $V_{G}$ is the grid voltage amplitude.

- $i_{G}^{-}=i_{G d}+i_{G q}$ is the grid currents' vector.

These two converters are implemented in the Matlab/Simulink Model.

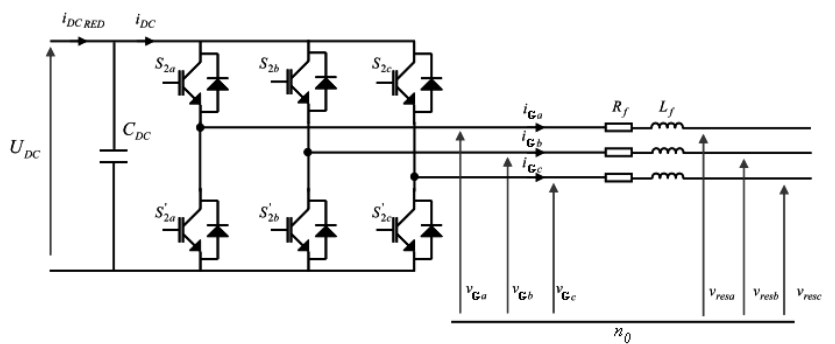

Fig. 6. Electric representation of the Grid-side converter. $R_{f}, L_{f}$ are filtering components.

\section{The Control Strategy}

Despite the complexity and nonlinearity of the kite's model, the KGS control strategy's aim can be divided into two objectives: the first aims at tracking a proposed eightfigured orbit, and the second's aim is to find and track an optimal tether radial velocity. As explained in [9], for a certain orbit the optimal tether radial velocity and the orbit's period are extracted based on the work of [1]. A Model Predictive Control (MPC) strategy that allows an optimal tracking under constraints of the generated orbit is then implemented. The interest in this paper is achieving tether radial velocity tracking by controlling the SM-PM rotation velocity, $V_{L}=\Omega_{S} / R$, taking into account wind speed variations. Fig.7 shows the general control scheme. In addition to the classical control of the rotation velocity, the currents and the voltages profiles, a maximum power point tracking (MPPT) algorithm is applied to follow wind variations.

\section{A. MS-PM Driving and Control Scheme}

As mentioned earlier, the control strategy distinguishes two cases: The KGS is installed on the grid, or it is used to supply a certain load. When connected to the electric grid the interest is to extract the maximum possible energy, meanwhile, for a certain load, the system should provide the required energy only.

The SM-PM's rotational velocity control as well as the generator torque control are guaranteed by the SM-PM-side converter. The kite applies a resistive torque $C_{R}$ that gives,

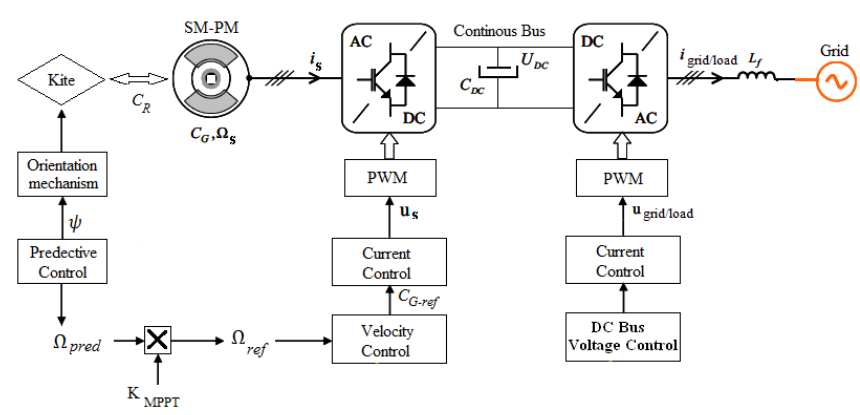

Fig. 7. General control scheme of the KGS.

when inserted in the mechanical equation, the rotation velocity $\Omega_{S}$, the velocity is corrected using a PI controller that yields a reference generator torque $C_{G r e f}$. When adapting Park representation of the synchronous machine and the converter, controlling the generator torque $C_{G}$ is equivalent to controlling the current $i_{s q}$ when asserting $i_{s d}=0$. As for the reference rotation velocity's profile, it is given by the model predictive control [9], then it is multiplied by a coefficient $K_{M P P T}$ whose value is obtained in the MPPT algorithm explained later.

The purpose of grid-side converter, in addition to converting the direct power to a fixed-frequency alternative power, or vice versa, is to:

- in the case of grid connection: to provide the grid with three balanced sinusoidal phase currents, whose amplitude depends on the bus-voltage.

- and for a load connection: to control the amplitude of the voltages supplying the load.

\section{B. Maximum Power Point Tracking (MPPT) Algorithm}

In the case of absence of wind speed measurement, the optimal radial velocity can be calculated according to standard wind-altitude curves. The MPPT algorithm is applied to amplify the obtained optimal velocity in order to maximize the generated power. Fig.8, shows the flowchart of the MPPT algorithm. The proposed algorithm calculates the average power during a period. By comparing this power with the power obtained during the previous period, the algorithm applies the reference optimal radial velocity after multiplying it with a suitable gain. The algorithm is effective because at high altitudes wind speed changes are slow compared to the orbit's period.

\section{Simulation And Results}

A simplified closed-orbit KGS with application of MPPT algorithm mentioned above is taken into consideration. The employed KGS's parameters are those of a prototype built and tested in Polytechnico di Torino [7]. They are shown on Table I. The proposed control scheme is applied on an eight-form orbit to find its corresponding generated electrical power. The orbit is defined by the following parametric equations:

$$
\begin{aligned}
& \theta(\tau)=72.5^{\circ}+20^{\circ} \sin (2 \tau) \\
& \phi(\tau)=20^{\circ} \sin (\tau)
\end{aligned}
$$




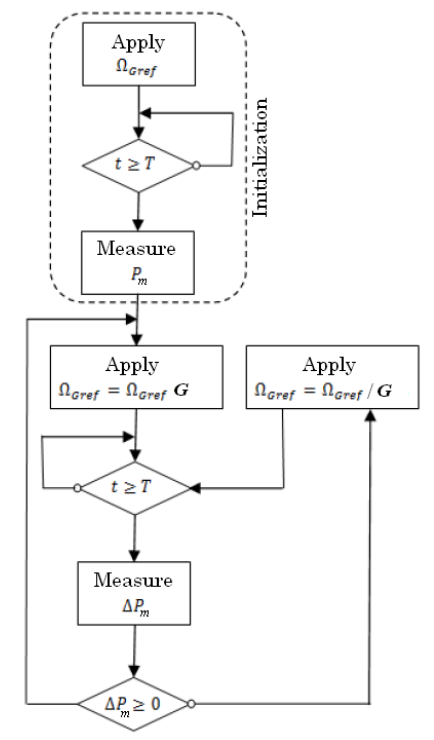

Fig. 8. Maximum Power Point Tracking (MPPT) algorithm.

with $\tau \in[0,2 \pi]$. As obtained in [9] depending on Argatov's

TABLE I

Kite Generator System Parameters

\begin{tabular}{|c||c||c|}
\hline$R$ & 0.3 & Rotor Diameter $(\mathrm{m})$ \\
\hline$V$ & 9 & Wind speed $(\mathrm{m} / \mathrm{sec})$ \\
\hline$\Omega_{\max }$ & 25 & Maximum rotation velocity $(\mathrm{rd} / \mathrm{sec})$ \\
\hline$\Gamma_{\max }$ & 40 & Motor maximum torque $(\mathrm{N} . \mathrm{m})$ \\
\hline$p$ & 7 & Pole's pairs number \\
\hline$A, m$ & $5,2.5$ & Kite's area $\left(\mathrm{m}^{2}\right)$ andmass $(\mathrm{kg})$ \\
\hline$\rho_{a}$ & 1.2 & Air density $\left(\mathrm{kg} / \mathrm{m}^{3}\right)$ \\
\hline$C_{L}, C_{D}$ & $1.5,0.15$ & Lift and Drag coefficient \\
\hline$r_{0}$ & 100 & Initial tether length $(\mathrm{m})$ \\
\hline
\end{tabular}

approach [2], the orbit's period is found to be $2.48 \mathrm{sec}$. The corresponding normalized optimal radial velocity is shown on Fig.9. Fig. 10 shows the orbit tracking resulted by applying optimal predictive control [9]. The resultant

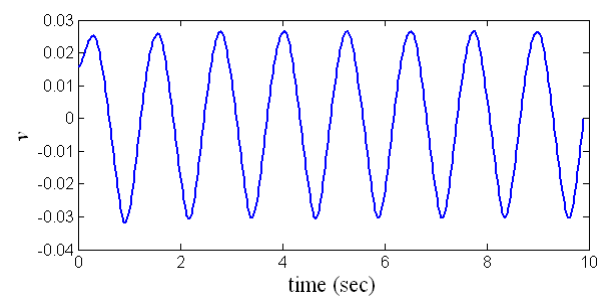

Fig. 9. Optimal normalized radial velocity.

tether's radial velocity $v$ as well as the traction force $F^{c, t r c}$ obtained from the kite model are transformed into a rotation velocity $\Omega_{S}$ and a resistive torque $C_{R}$ of the rotor. The transformation is done through multiplication by a constant, as in the following equations:

$$
\begin{aligned}
& \Omega_{S}=\frac{V}{R} \frac{v}{K} \\
& C_{R}=R F^{c, t r c} K
\end{aligned}
$$

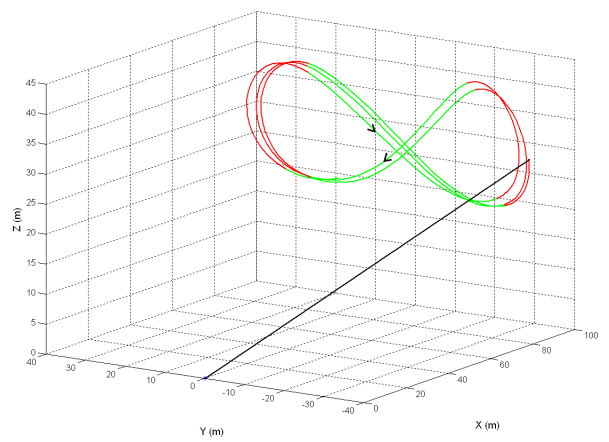

Fig. 10. Orbit Tracking using optimal predictive control

where $K$ is the gear box ratio. The obtained $\Omega_{S}$ and $C_{R}$ are then applied on the power transformation system Simulink model $^{3}$. The first result is that generating power using the KGS is guaranteed, which is shown by the product of the kite's resistive torque $C_{R}$ and the reference rotational velocity (Fig.11), if the velocity was successfully tracked. Velocity tracking is achieved by modifying the parameters of the rotation velocity PI corrector (Fig.12). As well as, the later figure shows how the reference velocity's amplitude varies when the wind speed $V$ is changed from $9 \mathrm{~m} / \mathrm{sec}$ to $10 \mathrm{~m} / \mathrm{sec}$ at time instant $\mathrm{t}=2 \mathrm{sec}$, by employing the MPPT algorithm. The next step is to transform the mechanical
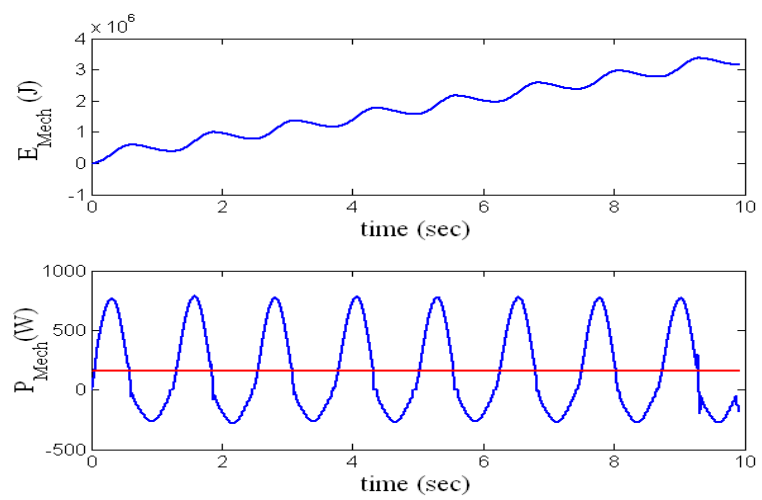

Fig. 11. Energy produced (above) and mechanical power generation (below) while tracking the orbit of eq.13. $P_{M}$ is the mean power.

power produced by the MS-PM into an electrical power that can be injected into the grid. This can be insured by tuning different control presented in the general control scheme (Fig.7). Figs.13 shows the machine phase current $I_{a S-M}$ and the DC bus voltage $U_{D C}$ for the variations of $\Omega_{G}$ between 1 and $2.5 \mathrm{sec}$. It can be noticed that $U_{D C}$ is well controlled with an error less than $0.9 \%$. Fig. 14 shows a grid phase current $I_{a-\text { grid }}$ and the grid phases voltages $V_{a, b, c}$. It can be noticed that the grid-side converter was successfully controlled to provide the grid with a standard three-phase voltage, and the current has only the $50 \mathrm{~Hz}$ harmonic.

\footnotetext{
${ }^{3}$ Sizing operation should be applied on the kite's torque and the radial velocity in order to satisfy the energy transformation system characteristics.
} 

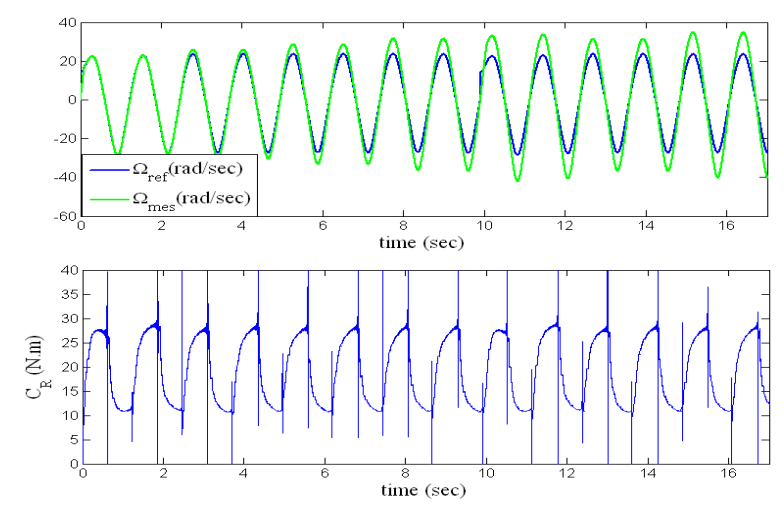

Fig. 12. Resistive torque $\left(C_{R}\right)$ and rotation velocity tracking with applying MPPT algorithm when wind speed $V$ is changed from $9 \mathrm{~m} / \mathrm{sec}$ to $10 \mathrm{~m} / \mathrm{sec}$.
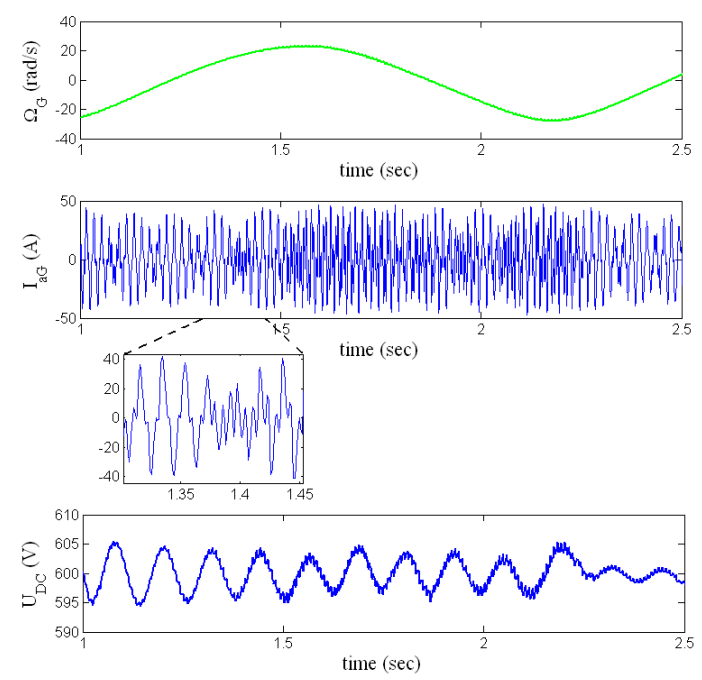

Fig. 13. Rotation Velocity $\left(\Omega_{G}\right)$, MS-PM phase current $\left(I_{a G}\right)$ and DC bus voltage $\left(U_{D C}\right)$

\section{CONCLUSION AND FURTHER WORKS}

\section{A. Conclusions}

A closed-orbit Kite Generator System with application of MPPT algorithm was considered in this paper. It was illustrated that for an eight-form orbit, the optimal radial velocity of the tether was calculated for a specific wind speed [9]. Using the kite model, the kite's traction force was calculated, and the corresponding resistive torque was applied on a Simulink model of the power transformation system. A maximum power point tracking (MPPT) algorithm was applied on the SM-PM's rotation velocity in order to insure maximum power production in the case of wind speed variations.

By controlling the MS-PM rotation velocity to follow the reference velocity profile generated by the MPPT algorithm, and controlling different electrical variables' loops, a maximum power in the range of 10 to $100 \mathrm{~kW}$ corresponding to the given orbit was generated and successfully integrated into the grid.
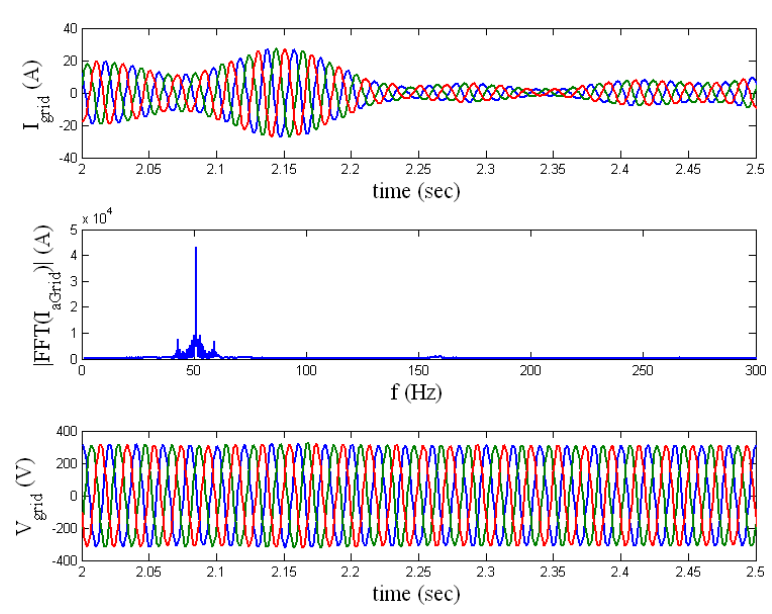

Fig. 14. Grid currents $\left(I_{a, b, c}\right)$, phase current's frequential analysis $\left(\left|F T T\left(I_{a}\right)\right|\right)$, and Grid voltages $\left(V_{a, b, c}\right)$.

\section{B. Further Works}

This work is a part of a collaboration project between Gipsa-lab and G2ELab. A reduced kite's model is under construction. The theoretical results in this paper will be applied to a HIL (Hardware in the loop) physical simulator, that is dedicated to real-time validation of control laws with insertion of physical elements that contribute to better replication of the real phenomena [10].

After assuring the basic operation of the KGS and its integration onto the grid, robustness study is to be considered. It regards the parameters' errors and major common disturbances, such as voltage dips and harmonics disturbances.

\section{REFERENCES}

[1] I. Argatov, P. Rautakorpi, and R. Silvennoinen. Estimation of the mechanical energy output of the kite wind generator. Renewable Energy, 34:1525-1532, 2009.

[2] I. Argatov and R. Silvennoinen. Energy conversion efficiency of the pumping kite wind generator. Renewable Energy, 35(5):1052-1060, 2010.

[3] M. Canale, L. Fagiano, M. Ippolito, and M. Milanese. Control of tethered airfoils for a new class of wind energy generator. In Proceedings of the 45th IEEE Conference on Decision and Control, 2006.

[4] M. Diehl. Real time optimization for Large Scale Nonlinear Processes. $\mathrm{PhD}$ thesis, University of Heidelburg, 2001.

[5] L. Fagiano, M. Milanese, and D. Piga. High-altitude wind power generation for renewable energy cheaper than oil. in Sustainable development: a challenge for European research, Brussels, May 2009.

[6] A. Ilzhofer, B. Houska, and M. Diehl. Nonlinear mpc of kites under varying wind conditions for a new class of large-scale wind power generators. International Journal Of Robust And Nonlinear Control, 17:1590-1599, 2007.

[7] L. Fagiano M. Canale and M. Milanese. Power kites for wind energy generation, fast predictive control of tethered airfoils. IEEE CONTROL SYSTEMS MAGAZINE, pages 25-38, 2007.

[8] M. Arnaiz martin. Modeling and control of kites for electric energy generation. Master's thesis, Grenoble INP, 2010.

[9] M.S.Ahmed, A.Hably, and S.Bacha. Power maximization of a closedorbit kite generator system. In 50th IEEE Conference on Decision and Control and European Control Conference, 2011.

[10] I. Munteanu, A.I. Bratcu, S. Bacha, D. Roye, and J. Guiraud. Hardware-in-the-loop-based simulator for a class of variable-speed wind energy conversion systems: Design and performance assessment. IEEE Transactions On Energy Conversion, 25:564-576, JUNE 2010. 